\title{
CD44 is a macrophage binding site for Mycobacterium tuberculosis that mediates macrophage recruitment and protective immunity against tuberculosis
}

\author{
Jaklien C. Leemans, ${ }^{1}$ Sandrine Florquin, ${ }^{2}$ Mirjam Heikens, ${ }^{1}$ Steven T. Pals, ${ }^{2}$ \\ Ronald van der Neut, ${ }^{2}$ and Tom van der Poll ${ }^{1,3}$ \\ ${ }^{1}$ Laboratory of Experimental Internal Medicine, \\ ${ }^{2}$ Department of Pathology, and \\ ${ }^{3}$ Department of Infectious Diseases, Tropical Medicine and AIDS, Academic Medical Center, University of Amsterdam, \\ Amsterdam, The Netherlands
}

\begin{abstract}
Cell migration and phagocytosis are both important for controlling Mycobacterium tuberculosis infection and are critically dependent on the reorganization of the cytoskeleton. Since CD44 is an adhesion molecule involved in inflammatory responses and is connected to the actin cytoskeleton, we investigated the role of CD44 in both these processes. Macrophage $(\mathrm{M} \phi)$ recruitment into M. tuberculosis-infected lungs and delayed-type hypersensitivity sites was impaired in CD44-deficient $\left(\mathrm{CD}^{-1} 4^{-/}\right)$mice. In addition, the number of T lymphocytes and the concentration of the protective key cytokine IFN- $\gamma$ were reduced in the lungs of infected $\mathrm{CD} 44^{-/-}$mice. The production of IFN- $\gamma$ by splenocytes of $C D 44^{-/-}$mice was profoundly increased upon antigen-specific stimulation. Flow cytometry analysis revealed that soluble CD44 can directly bind to virulent $M$. tuberculosis. Mycobacteria also interacted with $\mathrm{M} \phi$-associated CD44, as reflected by reduced binding and internalization of bacilli by $C D 44^{-/-} \mathrm{M} \phi s$. This suggests that CD44 is a receptor on M $\phi$ s for binding of M. tuberculosis. CD44-/- mice displayed a decreased survival and an enhanced mycobacterial outgrowth in lungs and liver during pulmonary tuberculosis. In summary, we have identified CD44 as a new M $\phi$ binding site for $M$. tuberculosis that mediates mycobacterial phagocytosis, $\mathrm{M} \phi$ recruitment, and protective immunity against pulmonary tuberculosis.
\end{abstract}

J. Clin. Invest. 111:681-689 (2003). doi:10.1172/JCI200316936.

\section{Introduction}

Mycobacterium tuberculosis is one of the most threatening microorganisms, causing more deaths annually than any other single human pathogen (1). Each year, over 8 million new cases of tuberculosis and 2 million deaths from this disease occur worldwide $(2,3)$. The increasing incidence of tuberculosis over the last decade has increased the need to define host factors that control resistance to tuberculosis.

Effective host defense against $M$. tuberculosis is primarily dependent on the interplay between macrophages (Mфs), T cells, and dendritic cells $(4,5)$. This interaction requires the migration and activation of leukocytes, which is dependent on the ability of cells to adhere to

Received for publication September 17, 2002, and accepted in revised form January 14, 2003.

Address correspondence to: Jaklien C. Leemans, Laboratory of Experimental Internal Medicine, Academic Medical Center,

University of Amsterdam, Meibergdreef 9, Room G2-105,

1105 AZ Amsterdam, The Netherlands. Phone: 31-20-5665910;

Fax: 31-20-6977192; E-mail: j.c.leemans@amc.uva.nl.

Conflict of interest: The authors have declared that no conflict of interest exists.

Nonstandard abbreviations used: macrophage $(M \phi)$; polymorphonuclear cell (PMN); postinfection (p.i.); PPD, purified protein derivative; staphylococcal enterotoxin A (SEA); staphylococcal enterotoxin B (SEB); macrophage inflammatory protein-1 $\alpha$ (MIP-1 $\alpha$ ); CD44 standard (CD44std); delayed-type hypersensitivity (DTH). each other or to the ECM via adhesion molecules. CD44 is a member of the hyaluronate receptor family of cell adhesion molecules, which has been shown to play a selective role in controlling lymphocyte migration $(6,7)$. CD44 is expressed on hematopoietic cells and is linked to cytoskeletal elements like hyaluronic acid, collagen, fibronectin, and osteopontin (8). It is necessary for extravasation of activated $\mathrm{T}$ cells into inflammatory sites (6), but it is not required for normal leukocyte circulation (7). In vitro experiments suggest that CD44 is also involved in cytoskeleton-dependent phagocytosis of heat-killed Staphylococcus aureus by polymorphonuclear cells (PMNs) (9) and in phagocytosis of apoptotic PMNs by human monocyte-derived M $\phi s$ (10).

Among mammals, CD44 is a highly conserved receptor (11), which suggests that CD44 is under strong evolutionary pressure and therefore must be an important molecule. Data on the in vivo role of CD44 during inflammatory responses are, however, limited. As indicated by studies on arthritis (12-15), contact hypersensitivity (7), and autoimmune encephalomyelitis (16), CD44 may play a role in the pathogenesis of inflammatory disorders, presumably by contributing to the migration of activated leukocytes to sites of inflammation. Although these studies reveal a role for CD44 during inflammatory responses, little is known about its in vivo role during infections with pathogenic microorganisms. A single study, using an inactivating $\mathrm{Ab}$ 
directed against CD44, suggested that this adhesion molecule is not needed for resistance against infection with Toxoplasma gondii (17). A potential role for CD44 in the immune response to $M$. tuberculosis is suggested by the observation that CD44high-expressing T cells (memory $\mathrm{T}$ cells) accumulate in the lungs of mice during infection with this pathogen (18-20).

In the present study we determined the role of CD44 in M. tuberculosis leukocyte migration and phagocytosis and investigated the significance of our findings in resistance against pulmonary tuberculosis. To do this, we infected $\mathrm{CD} 44^{-\gamma^{-}}$or $\mathrm{CD} 44^{+/+}$mice intranasally with a virulent strain of $M$. tuberculosis. Our results show that CD44 is important for the recruitment of M申s, the binding and uptake of $M$. tuberculosis by M $\phi$ s, and the protective immunity against lung tuberculosis in vivo. As studies in mice without functional $\alpha_{4}$ or $\alpha_{4} \beta_{7}$ integrin, P-selectin, ICAM-1, or complement receptor 3 (19, 21-23) have shown that these adhesion molecules are not involved in clearance of mycobacteria, the present study identifies a unique function for CD44 in resistance against mycobacterial infection.

\section{Methods}

Mice. Specific pathogen-free 8- to 10-week-old male and female CD44-deficient $\left(C D 44^{-/}\right)$mice on a C57BL/ 6 background (24) were a kind gift of A. Berns (Netherlands Cancer Institute, Amsterdam, The Netherlands). Examination of lymphocyte subsets in spleen and lymph nodes of $C D 44^{-/-}$mice demonstrated normal distribution and numbers of $\mathrm{CD}^{+}$and $\mathrm{CD}^{+} \mathrm{T}$ cells (24). Wild-type $\left(C D 44^{+/+}\right)$C57BL/ 6 mice were purchased from Iffa Credo (L'Arbresle, France). Animals were maintained in biosafety level 3 facilities. In all experiments, sex- and age-matched controls were used. The Animal Care and Use Committee of the University of Amsterdam approved all experiments.

Experimental infection. A virulent laboratory strain of M. tuberculosis H37Rv (American Type Culture Collection, Rockville, Maryland, USA) was grown for 4 days in liquid Dubos medium (Difco Laboratories, Detroit, Michigan, USA) supplemented with 0.5\% BSA (SigmaAldrich, St. Louis, Missouri, USA) and 0.01\% Tween-80. A replicate culture was incubated at $37^{\circ} \mathrm{C}$, harvested at mid-log phase, and stored in aliquots at $-70^{\circ} \mathrm{C}$. For each experiment, a vial was thawed and washed twice with sterile $0.9 \% \mathrm{NaCl}$. Tuberculosis was induced as described previously $(25,26)$. Briefly, mice were anesthetized by inhalation with isoflurane (Abbott Laboratories Ltd., Kent, United Kingdom) and infected intranasally with $1 \times 10^{5}$ live M. tuberculosis H37Rv bacilli in $50 \mu \mathrm{l}$ saline, as determined by viable counts on Middlebrook 7H11 (Difco, Detroit, Michigan, USA) agar plates. Bacterial counts recovered from lungs 1 day postinfection (p.i.) were shown previously to be similar to the number of bacteria in the inoculum (26).

Lung cell differentiation. Pulmonary-cell suspension was obtained using an automated disaggregation device (Medimachine System; DAKO A/S, Glostrup, Denmark) and resuspended in medium. Erythrocytes were lysed with ice-cold isotonic $\mathrm{NH}_{4} \mathrm{Cl}$ solution, and the remaining cells were washed twice with RPMI. Total leukocytes in pulmonary-cell suspensions were counted using a hemacytometer and Turk's solution (Merck KGaA, Darmstadt, Germany). The percentages of M $\phi s$, PMNs, and lymphocytes were determined using cytospin preparations stained with modified Giemsa stain (Diff-Quik; Baxter Healthcare Corp., McGraw Perk, Illinois, USA).

FACS analysis. Pulmonary-cell suspensions obtained from infected mice were analyzed by FACS (Becton Dickinson and Co., Franklin Lakes, New Jersey, USA) as described previously (26). Cells were brought to a concentration of $4 \times 10^{6}$ cells $/ \mathrm{ml}$ FACS buffer (PBS supplemented with $0.5 \% \mathrm{BSA}, 0.01 \% \mathrm{NaN}_{3}$ and $100 \mathrm{mM}$ EDTA). Immunostaining for cell surface molecules was performed for 30 minutes at $4^{\circ} \mathrm{C}$ using directly labeled $\mathrm{Ab}$ 's against CD3 (CD3-phycoerythrin), CD4 (CD4CyChrome), and CD8 (CD8-FITC and CD8-peridinin chlorophyl protein). All Ab's were used in concentrations recommended by the manufacturer (Pharmingen, San Diego, California, USA). To correct for nonspecific staining, an appropriate control Ab (rat IgG2; Pharmingen) was used. Cells were fixed with $2 \%$ paraformaldehyde, and surface molecules were analyzed by gating of the $\mathrm{CD}^{+}$ population. The number of positive cells was obtained by setting a quadrant marker for nonspecific staining.

Histology and immunohistochemistry. Lungs were removed 2 or 5 weeks after inoculation with M. tuberculosis, fixed for 24 hours in $4 \%$ paraformaldehyde in PBS for 24 hours, and embedded in paraffin. For the delayed-type hypersensitivity (DTH) response experiment, footpads were removed from antigen-challenged mice following immunization with heat-killed M. tuberculosis. After formalin fixation, specimens were decalcified in formic acid and embedded in paraffin. H\&Estained slides were coded and semiquantitatively scored for inflammatory infiltrates and lung granuloma formation by a pathologist. The presence of $\mathrm{CD} 44^{+}$cells, granulocytes, and M $\phi$ s was demonstrated by immunohistochemistry. Slides were deparaffinized, and endogenous peroxidase activity was quenched by a solution of methanol with $0.03 \% \mathrm{H}_{2} \mathrm{O}_{2}$. For $\mathrm{CD} 44$ staining, slides were then treated with $10 \mathrm{mM}$ sodium citrate solution (pH 6.0) for 10 minutes at $98^{\circ} \mathrm{C}$ in a microwave oven, incubated with rat anti-mouse CD44 IgG1 (KM114; Pharmingen), and then further incubated with rabbit anti-rat-biotin (DAKO A/S) and streptavidin-ABC solution (DAKO A/S). For color development, $1 \% \mathrm{H}_{2} \mathrm{O}_{2}$ and 3,3'-di-aminobenzidine tetrachloride (DAB; SigmaAldrich) in Tris- $\mathrm{HCl}$ was used. The sections were mounted in glycerin gelatin without counterstaining and analyzed. For granulocyte staining, slides were digested with a solution of $0.25 \%$ pepsine (SigmaAldrich) in $0.01 \mathrm{M} \mathrm{HCl}$; for $\mathrm{M} \phi$ staining, slides were digested with $0.1 \%$ trypsin (Sigma-Aldrich). Granulocyte and $M \phi$ sections were then incubated in $10 \%$ normal goat serum (DAKO A/S) and exposed, respectively, to FITC-labeled anti-mouse Ly-6G mAb (Pharmingen) 
or rat anti-mouse F4/80 IgG2b mAb (Serotec Ltd., Oxford, United Kingdom). For staining of granulocytes, slides were incubated with rabbit anti-FITC Ab (DAKO $\mathrm{A} / \mathrm{S}$ ) followed by a further incubation with a biotinylated swine anti-rabbit $\mathrm{Ab}(\mathrm{DAKO} \mathrm{A} / \mathrm{S})$. For $\mathrm{M} \phi$ staining, slides were incubated with goat anti-rat-HRP (Southern Biotechnology Associates, Birmingham, Alabama, USA). Slides were finally incubated in a streptavidin$\mathrm{ABC}$ solution (DAKO A/S) and developed using 1\% $\mathrm{H}_{2} \mathrm{O}_{2}$ and $\mathrm{DAB}$ (Sigma-Aldrich) in Tris- $\mathrm{HCl}$. The slides were counterstained with hematoxylin and evaluated by a pathologist blinded to the genotype of the animals. Splenocyte stimulation. We obtained single-cell suspensions by crushing spleens through a $40-\mu \mathrm{m}$ cell strainer (Becton Dickinson and Co.). Erythrocytes were lysed with ice-cold isotonic $\mathrm{NH}_{4} \mathrm{Cl}$ solution $\left(155 \mathrm{mM} \mathrm{NH}_{4} \mathrm{Cl}\right.$, $10 \mathrm{mM} \mathrm{KHCO}, 100 \mathrm{mM}$ EDTA [pH 7.4]), and the remaining cells were washed twice with RPMI 1640 (BioWhittaker Europe, Verviers, Belgium). To assess antigen-specific immune responses, cells were suspended in medium (RPMI 1640, 10\% FCS, $1 \%$ antibiotic-antimycotic [GIBCO BRL; Life Technologies Inc., Rockville, Maryland, USA]), seeded in 96-well round-bottomed culture plates at a cell density of $1 \times 10^{6}$ cells per well in triplicate, and stimulated with $20 \mu \mathrm{g} / \mathrm{ml}$ tuberculin purified protein derivative (PPD; Statens Seruminstitut, Copenhagen, Denmark). For stimulation of splenocytes of uninfected $\mathrm{CD}_{4} 4^{+/+}$and $\mathrm{CD} 44^{-/-}$mice, cells were stimulated with $10 \mu \mathrm{g} / \mathrm{ml}$ staphylococcal enterotoxin B (SEB; Sigma-Aldrich), $7 \mu \mathrm{g} / \mathrm{ml}$ staphylococcal enterotoxin A (SEA; Sigma-Aldrich), or coated anti-CD3 (clone 1452C11; homemade) and $1 \mu \mathrm{g} / \mathrm{ml}$ anti-CD28 (clone 37.51; Pharmingen) Ab's. Supernatants were harvested after a 48-hour incubation at $37^{\circ} \mathrm{C}$ in $5 \% \mathrm{CO}_{2}$, and cytokine levels were analyzed by ELISA.

$\mathrm{CD} 44^{+/+}$and $\mathrm{CD} 44^{-/-} M \phi$ stimulation. We isolated M $\mathrm{s}$ from $C D 44^{+/+}$and $C D 44^{-/}$mice by washing the peritoneal cavity with RPMI 1640 supplemented with 10\% FCS. Collected cells were allowed to adhere to 96-well tissue-culture plates $\left(10^{5}\right.$ cells per well) for 1 hour at $37^{\circ} \mathrm{C}$, after which nonadherent cells were removed by rinsing of the cell monolayer with medium. More than $95 \%$ of the cells were M $\phi s$, as identified by cytospin preparations stained with modified Giemsa stain. M $\phi$ monolayers were infected with M. tuberculosis in RPMI 1640 and 10\% FCS at a bacteria/M $/$ ratio (MOI) of 10 , and then incubated for 24 hours at $37^{\circ} \mathrm{C}$; then supernatants were aspirated and cytokine levels were analyzed by ELISA.

Cytokine measurements. IFN- $\gamma$, IL-2, IL-4, IL-10, TNF- $\alpha$, and M $\phi$ inflammatory protein- $1 \alpha$ (MIP-1 $\alpha$ ) were measured in lung homogenates, spleen cell supernatants, and $M \phi$ supernatants by specific ELISAs using matched $\mathrm{Ab}$ pairs according to the manufacturer's instructions (R\&D Systems Inc., Minneapolis, Minnesota, USA).

Binding and phagocytosis of $M$. tuberculosis by $\mathrm{CD}_{4} 4^{+/+}$and $C D 44^{-/-} M \phi$ s. M $\phi$ s were isolated from $C D 44^{+/+}$and $\mathrm{CD} 44^{-/-}$mice as described above. Binding and phagocytosis of M. tuberculosis were determined as described previously $(23,27)$. Briefly, $\mathrm{M} \phi$ monolayers $\left(10^{5}\right.$ cells per well) were infected with M. tuberculosis in RPMI 1640 and $10 \%$ FCS at an MOI of 10, and then incubated for 2 hours at $37^{\circ} \mathrm{C}$, after which supernatants were aspirated. Each well was washed three times with RPMI 1640 and $10 \%$ FCS to remove the remaining nonadherent mycobacteria. For assessment of mycobacterial load, cells remaining attached to the tissue culture wells were incubated with sterile distilled $\mathrm{H}_{2} \mathrm{O}$ with $0.1 \%$ dodecyl sulfate sodium salt (Merck KGaA) for 10 minutes at $25^{\circ} \mathrm{C}$. After a serial tenfold dilution of the cell lysate, the number of mycobacteria that were associated with the M $\phi$ s was determined by plating on Middlebrook 7H11, and CFUs were enumerated after 21 days. To assess whether bacilli were phagocytosed, we infected $M \phi s$ for 2 and 17 hours at an MOI of 2, after which cells were washed three times with PBS, fixed with $2 \%$ paraformaldehyde, and removed from the plate. Cytospins were made, stained with Ziehl-Neelsen stain for acid-fast bacilli, and counterstained with $0.1 \%$ methylene blue stain. At least 100-200 cells were counted on each cytospin. The number of intracellular bacilli in each $M \phi$ was counted. Cell viability of $M \phi$ cultures was assessed from duplicate wells by trypan blue exclusion and appeared similar (>95\%) in both groups.

Binding of CD44 to M. tuberculosis. M. tuberculosis $\mathrm{H} 37 \mathrm{Rv}$ bacteria $\left(2 \times 10^{5}\right)$ were incubated for 30 minutes at $37^{\circ} \mathrm{C}$ with $1 \mathrm{ng}$ human soluble CD44 standard (CD44std) protein (Bender MedSystems, Vienna, Austria) or with diluent in octuplicate. Subsequently, mycobacteria were centrifuged for 15 minutes at $2,000 \mathrm{~g}$ and incubated with a FITC-labeled mouse anti-human CD44std Ab (IgG1, clone SFF304; Bender MedSystems) for 30 minutes on ice. After incubation, mycobacteria were centrifuged, washed with FACS buffer, and fixed with $2 \%$ paraformaldehyde. CD44 binding was analyzed on a FACScan (Becton Dickinson and Co.).

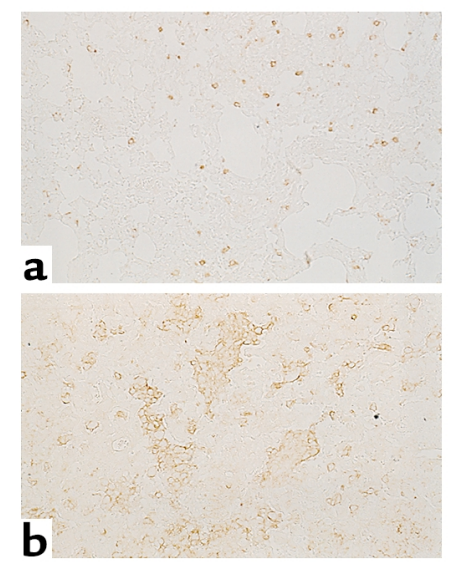

\section{Figure 1}

Expression of CD44 in lung tissue of $C D 44^{+/+}$mice after intranasal infection with $1 \times 10^{5} \mathrm{M}$. tuberculosis. Representative view of the lung of an uninfected mouse stained for CD44, showing only a few CD44+ passenger leukocytes (a), compared with the lung of a mouse 5 weeks after M. tuberculosis infection, showing a prominent influx of $\mathrm{CD} 44^{+}$ leukocytes (b). $\times 50$. 
Table 1

Effect of CD44 deficiency on cellular composition of total lung cells during tuberculosis

$$
\text { Cells } \times 10^{4} / \mathrm{ml} \quad \% \mathrm{M} \phi \mathrm{s} \quad \% \mathrm{PMNs} \quad \% \text { Lymphocytes }
$$

2 weeks p.i.

\begin{tabular}{|c|c|c|c|c|}
\hline$C D 44^{+/+}$ & $870 \pm 383$ & $27.0 \pm 3.1$ & $47.9 \pm 1.3$ & $25.1 \pm 3.0$ \\
\hline$C D 44^{-/-}$ & $877 \pm 273$ & $12.5 \pm 2.1^{\mathrm{A}}$ & $66.1 \pm 0.7^{\mathrm{A}}$ & $21.4 \pm 2.4$ \\
\hline \multicolumn{5}{|c|}{5 weeks p.i. } \\
\hline $244^{+/+}$ & $2,754 \pm 655$ & $30.3 \pm 2.5$ & $32.0 \pm 2.5$ & $37.8=$ \\
\hline$D 44^{-/-}$ & $3,710 \pm 415^{\mathrm{A}}$ & $29.5 \pm 2.1$ & $45.9 \pm 2.9^{\mathrm{A}}$ & $24.5 \pm$ \\
\hline
\end{tabular}

Leukocytes in lungs of $C D 44^{+/+}$and $C D 44^{-/-}$mice infected for 2 and 5 weeks with $M$. tuberculosis. Cells from eight mice per group were counted and differentiated on cytospin preparations stained with modified Giemsa stain. ${ }^{A} P<0.05, C D 44^{-/-}$mice vs. CD $44^{+/+}$mice.

Enumeration of bacteria. Groups of eight mice per time point were sacrificed 2 or 5 weeks p.i., and lungs, liver, and spleen were removed aseptically. Organs were homogenized with a tissue homogenizer (BioSpec Products Inc., Bartlesville, Oklahoma, USA) in 5 volumes of sterile $0.9 \% \mathrm{NaCl}$, and tenfold serial dilutions were plated on Middlebrook 7H11 agar plates to determine bacterial loads. Colonies were counted after a 21-day incubation period at $37^{\circ} \mathrm{C}$. For cytokine measurements, lung homogenates were diluted 1:1 in lysis buffer $(150$ $\mathrm{mM} \mathrm{NaCl}, 15 \mathrm{mM}$ Tris, $1 \mathrm{mM} \mathrm{MgCl}_{2}$ [pH 7.4], $1 \mathrm{mM}$ $\mathrm{CaCl}_{2}, 1 \%$ Triton, $20 \mathrm{ng} / \mathrm{ml}$ pepstatin A, $20 \mathrm{ng} / \mathrm{ml}$ leupeptin, and $20 \mathrm{ng} / \mathrm{ml}$ aprotinin) and incubated on ice for 30 minutes. Supernatants were sterilized using a $0.22-\mu \mathrm{m}$ filter (Corning Inc., Corning, New York, USA) and frozen at $-20^{\circ} \mathrm{C}$ until assays were performed.

Delayed-type hypersensitivity response to $P P D$. To measure DTH responses, we examined the swelling responses of footpads in mice. Briefly, $C D 44^{+/+}$and $C D 44^{-/-}$mice $(n=5)$ were immunized intradermally at the base of the tail with $0.1 \mathrm{mg}$ of heat-killed M. tuberculosis H37Ra (Difco Laboratories) in $0.1 \mathrm{ml}$ of mineral oil (Sigma-Aldrich). Twelve days after immunization, mice were challenged with $40 \mu \mathrm{g}$ PPD in saline into one hind footpad and with saline alone in the other. Measurements of footpad thickness were performed with a Mitutoyo model 7326 engineer's micrometer (Mitutoyo MTI Corp., Aurora, Illinois, USA) before and 24 hours after the PPD challenge. The increase in footpad thickness was calculated as the difference in swelling between the 0 - and 24-hour measurements. Specific DTH reactivity was calculated as the difference between the swelling of the PPD-injected footpads and the swelling of the saline-injected footpads.

Statistical analysis. All values are expressed as mean \pm SEM. Comparisons were done with Mann-Whitney $U$ tests. For comparison of survival curves, Kaplan-Meier analysis with a log rank test was used. Values of $P<0.05$ were considered statistically significant.

\section{Results}

Accumulation of $\mathrm{CD}_{4} 4^{+}$cells in the pulmonary compartment during $M$. tuberculosis infection. Previous studies have documented that CD $44^{\text {high }}$ cells accumulate in mouse lungs during $M$. tuberculosis infection (18-20). To verify this observation in our model, we studied the expression of CD44 in lung tissue of wild-type mice infected intranasally with $M$. tuberculosis. Immunohistochemical staining of CD44 revealed a strong increase in the number of CD $44^{+}$cells in lung tissue of mice with $M$. tuberculosis (Figure 1, a vs. b).

$C D 44$ promotes the recruitment of $M \phi$ s and lymphocytes to infected lungs. To investigate whether CD44 is involved in leukocyte recruitment, we assessed the numbers and phenotypes of pulmonary leukocytes from $\mathrm{CD}_{44^{+/+}}$and $\mathrm{CD} 44^{-/-}$mice during tuberculosis (Table $1)$. For this, we intranasally infected eight mice per group with $1 \times 10^{5} \mathrm{CFU} M$. tuberculosis and sacrificed them after 2 or 5 weeks. While the absolute number of leukocytes in lungs of $C D 44^{+/+}$and $C D 44^{-/-}$mice was similar 2 weeks p.i., $C D 44^{-/-}$mice had almost $50 \%$ less $\mathrm{M \phi s}$ in their pulmonary compartment than $C D 44^{+/+}$ mice $(P<0.05)$. At 5 weeks p.i., lungs of $C D 44^{-/-}$mice contained more leukocytes than lungs of $C D 44^{+/+}$ mice $(P<0.05)$. At this time point the percentage of M $\phi$ s was similar in both mouse strains. The percentage of pulmonary lymphocytes of CD44-/- mice was, however, significantly reduced compared with that of $C D 44^{+/+}$mice 5 weeks p.i. $(P<0.05)$. Subtyping of lymphocytes at 2 weeks showed that the percentages of $\mathrm{CD}^{+}$and $\mathrm{CD}^{+} \mathrm{T}$ cells were similar in both groups (data not shown). Five weeks p.i., CD44-/- mice displayed a lower percentage of CD3/CD $4^{+}$cells $(59 \pm 2$ vs. $64 \pm 0.4)$, whereas the percentage of CD3/CD8 ${ }^{+} \mathrm{T}$ cells was similar in both strains (data not shown).
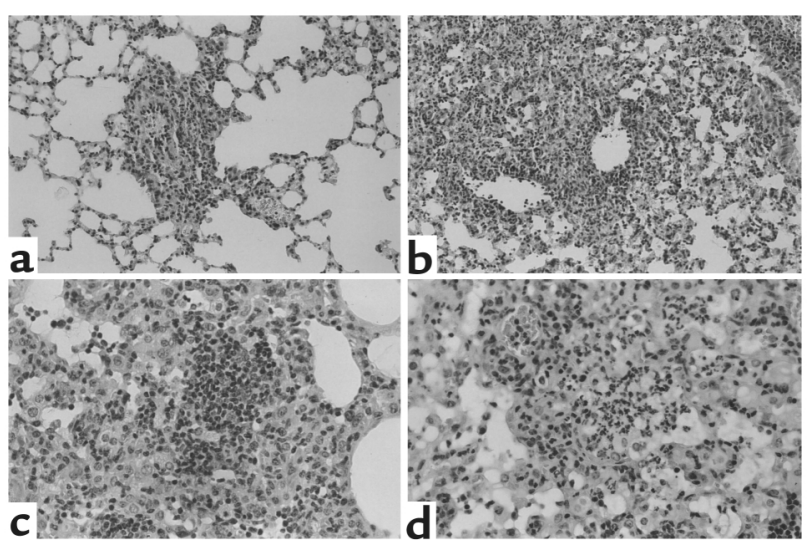

\section{Figure 2}

Representative histopathological sections of lungs of $\mathrm{CD} 44^{+/+}$(a and c) and $C D 44^{-/-}$(b and d) mice after inoculation with $M$. tuberculosis. (a) Characteristic small granuloma in the lung of a $C D 44^{+/+}$mouse 2 weeks after $M$. tuberculosis infection (magnification, $\times 50$; H\&E staining). (b) In contrast, $C D 44^{-/-}$mice were unable to form well-shaped granulomas, and lungs displayed a diffuse inflammatory infiltrate largely composed of PMNs (magnification, $\times 50$; H\&E staining). (c) At 5 weeks after infection, a diffuse, almost confluent inflammation was observed in the lungs of $C D 44^{+/+}$mice. Lymphocytes and M $\phi$ s represented the majority of leukocytes (magnification, $\times 100 ; \mathrm{H} \& \mathrm{E}$ staining). (d) At the same time point, lungs of $C D 44^{-/-}$mice showed a diffuse granulocytic inflammatory infiltrate (original magnification, $\times 100$; H\&E staining). 

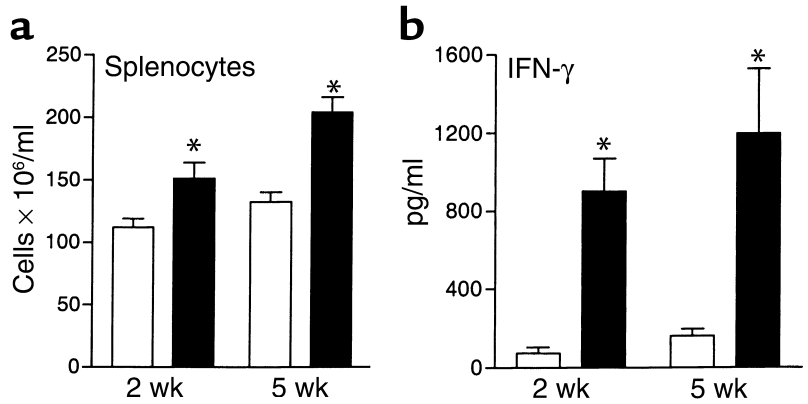

\section{Figure 3}

Effect of CD44 deficiency on cellularity and IFN- $\gamma$ response of splenocytes of $C D 44^{+/+}$mice (white bars) and CD44-/- mice (black bars) 2 and 5 weeks p.i. Splenocytes were dissociated into single-cell suspension, counted, and stimulated $\left(1 \times 10^{6}\right.$ cells per well) for 48 hours with PPD. (a) $C D 44^{-/-}$mice have increased cellularity of spleens compared with $\mathrm{CD} 44^{+/+}$mice. (b) Stimulated splenocytes from infected $C D 44^{-/-}$mice release more IFN- $\gamma$ in response to PPD than splenocytes from infected $\mathrm{CD} 44^{+/+}$mice. Data are mean \pm SEM of eight mice per group. ${ }^{*} P<0.05$.

The percentage of PMNs in the lungs of $C D 44^{-/-}$mice was increased compared with that of $C D 44^{+/+}$mice at both time points $(P<0.05)$.

Reduced granuloma formation in $\mathrm{CD} 44^{-/-}$mice. We next investigated the contribution of CD44 to the histopathology of lungs from $M$. tuberculosis-infected mice. At 2 weeks after infection, lungs of $C D 44^{+/+}$mice displayed sharply demarcated granulomas, generally located around small bronchi and vessels. These granulomas were composed of lymphocytes and M $\phi$ s (Figure $2 \mathrm{a}$ ). On the contrary, $C D 44^{-/-}$mice were unable to form well-shaped granulomas in reaction to M. tuberculosis but displayed enlarged and disorganized lesions that contained predominantly PMNs (Figure $2 \mathrm{~b}$ ). At 5 weeks after infection, the inflammation became more diffuse in $\mathrm{CD}_{4} 4^{+/+}$and $\mathrm{CD} 44^{-/-}$mice. Whereas the infiltrate in lungs from $\mathrm{CD} 44^{+/+}$mice was still predominantly composed of lymphocytes and M $\phi$ s (Figure 2c), PMNs were more dominant in lungs of $\mathrm{CD} 44^{-/-}$mice (Figure 2d). Moreover, edema and pleuritis were more pronounced in $\mathrm{CD} 44^{-/-}$than in $\mathrm{CD} 44^{+/+}$mice.

Accumulation of type 1 cells in spleens of $\mathrm{CD}_{44^{-/}}$mice. Because CD44 has been implicated in migration of leukocytes to sites of inflammation, we determined the number of cells in the spleen during tuberculosis in $\mathrm{CD} 44^{-/-}$and $\mathrm{CD} 44^{+/+}$mice. At 2 and 5 weeks p.i., $35 \%$ and $54 \%$ more cells, respectively, were recovered from spleens of $C D 44^{-/-}$mice than from spleens of $C D 44^{+/+}$mice $(P<0.05)$ (Figure 3a). To obtain insight into the functional properties of splenocytes, we assessed their capacity to produce type 1 (IFN- $\gamma$ ) and type 2 (IL-4) cytokines upon antigen-specific stimulation with PPD. Intriguingly, splenocytes of $C D 44^{-/-}$mice secreted 12 times $(P<0.05)$ and 7.5 times $(P<0.05)$ more of the protective IFN- $\gamma$ at, respectively, 2 and 5 weeks p.i. than did splenocytes of $\mathrm{CD}_{4} 4^{+++}$mice (Figure 3b). IL-4 was undetectable in all samples. To exclude that the enhanced IFN- $\gamma$ production of $C D 44^{-/-}$splenocytes was constitutively present, we stimulated splenocytes from five uninfected $C D 44^{-/-}$and $C D 44^{+/+}$mice with four different stimulators $(\alpha \mathrm{CD} 3 / 28, \mathrm{SEB}, \mathrm{SEA}$, and PPD). We found that CD44 deficiency per se did not influence IFN- $\gamma$ release by naive splenocytes (data not shown).

Reduced cytokine concentrations in the absence of CD44. To obtain insight into the influence of CD44 on local type 1 and type 2 cytokine concentrations during tuberculosis, we measured IFN- $\gamma$ and IL-2 (type 1), and IL-4 and IL-10 (type 2), in lung homogenates at 2 and 5 weeks p.i. At both time points, the pulmonary levels of these cytokines were lower in $\mathrm{CD} 44^{-/-}$than in $\mathrm{CD} 44^{+/+}$mice (Table 2). To assess the impact of CD44 deficiency on cytokine and chemokine expression by M $\phi$ s, we infected isolated $\mathrm{CD}_{44^{+/+}}$and $\mathrm{CD} 44^{-/-} \mathrm{M} \phi$ s with live M. tuberculosis for 24 hours. We found that the concentrations of TNF- $\alpha$, MIP- $1 \alpha$, and IFN- $\gamma$ in supernatants of $C D 44^{-/-}$M $\phi$ s were lower than in supernatants of $C D 44^{+/+} \mathrm{M} \phi$ s (Table 3 ).

$M \phi$-associated CD44 mediates binding and phagocytosis of M. tuberculosis. Adhesion molecules can play a role in the pathogenesis of microbial infection by mediating phagocytosis of pathogens (28). To determine whether CD44 expressed on M $\phi$ s mediates binding of the tubercle bacillus, we infected isolated $\mathrm{CD} 44^{+/+}$and $\mathrm{CD} 44^{-/-}$ M $\phi$ s with live M. tuberculosis for 2 hours and determined the number of CFUs by plating $M \phi$ lysates. As shown in Figure $4 \mathrm{a}, \mathrm{CD} 44^{+/+} \mathrm{M} \phi$ s contained a large mycobacterial load. Interestingly, eightfold less M. tuberculosis was associated with $C D 44^{-/-} \mathrm{M} \phi$ s than with $C D 44^{+/+} \mathrm{M} \phi \mathrm{s}$ $(P<0.05)$. Additionally, we identified acid-fast bacilli internalized by M $\phi$ s with Ziehl-Neelsen stain to investigate whether phagocytosis of $M$. tuberculosis by $C D 44^{-/}$ $\mathrm{M} \phi \mathrm{s}$ was impaired (Figure $4 \mathrm{~b}$ ). The average number of engulfed bacilli per $\mathrm{M} \phi$ was significantly lower in $\mathrm{CD} 44^{-/-} \mathrm{M} \phi s(0.18$ per $\mathrm{M} \phi)$ than in $\mathrm{CD} 44^{+/+} \mathrm{M} \phi s(0.31$ per $\mathrm{M} \phi, P<0.05)$ after 2 hours. After 17 hours, almost three times fewer bacilli were phagocytosed by $C D 44^{-/-}$ $\mathrm{M} \phi \mathrm{s}(0.23$ per $\mathrm{M} \phi)$ than by $\mathrm{CD} 44^{+/+} \mathrm{M} \phi \mathrm{s}(0.63$ per $\mathrm{M} \phi$, $P<0.05)$. Together, these results indicate that in this in vitro model, $\mathrm{M} \phi$-associated $\mathrm{CD} 44$ contributes to the binding and subsequent uptake of $M$. tuberculosis.

CD44 binds to M. tuberculosis. The role of CD44 in mediating mycobacterial association was further investigated by incubation of human recombinant CD44std with

\section{Table 2}

Effect of CD44 deficiency on M. tuberculosis-mediated induction of type 1 cytokines (IFN- $\gamma$ and IL-2) and type 2 cytokines (IL-4 and IL-10) in lungs

$\begin{array}{lllll}\mathrm{pg} / \mathrm{ml} & \text { IFN- } \gamma & \text { IL-2 } & \text { IL-4 } & \text { IL-10 }\end{array}$

2 weeks p.i.

$\begin{array}{lllll}C D 44^{+/+} & 165.0 \pm 10.0 & 488.9 \pm 37 & 3,699 \pm 100 & 359.4 \pm 33.2\end{array}$

$\begin{array}{lllll}C D 44^{-/} & 110.0 \pm 6.8^{\mathrm{A}} & 329.7 \pm 28.8^{\mathrm{A}} & 2,859 \pm 216^{\mathrm{A}} & 302.3 \pm 19.8\end{array}$

5 weeks p.i.

$\begin{array}{lllll}C D 44^{+/+} & 212.5 \pm 16.4 & 681.0 \pm 46.7 & 2,115 \pm 145 & 211.0 \pm 23.6\end{array}$

$\begin{array}{lllll}C D 44^{-/} & 168.6 \pm 17.7 & 541.0 \pm 23.5^{\mathrm{A}} & 1,418 \pm 165^{\mathrm{A}} & 159.8 \pm 19.9\end{array}$

Cytokines were measured in lung homogenates of $C D 44^{+/+}$and $C D 44^{-/-}$mice 2 and 5 weeks p.i. Data represent the mean \pm SEM of eight mice. ${ }^{A} P<0.05$. 


\section{Table 3}

Effect of CD44 deficiency on M. tuberculosis-mediated induction of cytokines (TNF- $\alpha$ and IFN- $\gamma$ ) and chemokines (MIP- $1 \alpha)$ in supernatants of stimulated $\mathrm{M} \phi \mathrm{s}$

\begin{tabular}{lclc}
\hline $\mathrm{Pg} / \mathrm{ml}$ & TNF- $\alpha$ & IFN- $\gamma$ & \multicolumn{1}{c}{ MIP-1 $\alpha$} \\
$C D 44^{+/+}$ & $432.1 \pm 79.4$ & $42 \pm 5.1$ & $1,823.7 \pm 217$ \\
$C D 44^{-/-}$ & $375.8 \pm 99.5$ & $14 \pm 5.9^{\mathrm{A}}$ & $1,158.5 \pm 148.5^{\mathrm{A}}$ \\
\hline
\end{tabular}

Cytokines were measured in supernatants of $C D 44^{+/+}$and $C D 44^{-/-}$M $\phi$ s 24 hours after infection with live $M$. tuberculosis. Data represent the mean \pm SEM of four mice. ${ }^{A} P<0.05$.

live M. tuberculosis. Flow cytometry analysis of surface binding of tubercle bacilli to CD44 demonstrated a clear shift of fluorescence intensity (Figure 5). An almost three times higher fluorescence intensity was observed in M. tuberculosis incubated with CD44std and subsequently stained with anti-CD44-FITC (mean channel fluorescence $94 \pm 8$ ) than in mycobacteria treated with only anti-CD44-FITC (mean channel fluorescence $34 \pm 14$ ) (Figure $5, P<0.05$ ). In addition, the majority of mycobacteria stained negative when incubated with anti-CD44std-FITC (mean 15.4\% \pm 4.8\%), while $50.6 \% \pm 1.9 \%$ of $M$. tuberculosis incubated with recombinant $\mathrm{CD} 44$ std became FITC-positive, indicating direct binding of CD44 to mycobacteria $(P<0.05)$.

Increased bacterial load in lungs and liver of $\mathrm{CD} 44^{-/-}$mice. We next investigated the impact of CD44 deficiency on the control of mycobacterial growth. As shown in Figure 6 , from 2 weeks to 5 weeks, $M$. tuberculosis grew more slowly in $\mathrm{CD}_{44^{+/+}}$mice than in $\mathrm{CD} 44^{-/-}$mice. As a consequence, $C D 44^{-/-}$mice had 2.6-fold and sevenfold more mycobacteria in lungs than did $C D 44^{+/+}$mice at 2 weeks p.i. $(P<0.05)$ and 5 weeks p.i. $(P<0.05)$, respectively. In addition, livers of $C D 44^{-/-}$mice contained more mycobacteria than livers of $C D 44^{+/+}$mice $(P<0.05$ at 5 weeks). In contrast, the numbers of $M$. tuberculosis CFUs recovered from spleens were similar in both mouse strains at each time point.

Reduced survival in M. tuberculosis-infected CD44-/- mice. To study whether CD44 deficiency also influenced survival, $C D 44^{-/-}$and $C D 44^{+/+}$mice ( $n=10$ per group) were intranasally infected with $M$. tuberculosis, and survival was monitored for 7 months. Compared with $C D 44^{+/+}$ mice, $C D 44^{-/-}$mice showed a significant reduction in survival (Figure 7). At 210 days p.i., survival of CD44-/mice was $60 \%$, whereas all $C D 44^{+/+}$mice remained alive during this observation period $(P<0.05)$. Thus, differences in bacterial loads in lungs and liver were paralleled by differences in survival, supporting a protective role for CD44 in the immune response to M. tuberculosis.

CD44 is important for mononuclear cell recruitment to DTH sites. The recruitment of leukocytes into inflamed areas is critical for the development of DTH responses. To study the role of CD44 in leukocyte migration more extensively, we determined DTH responses in CD44-/and $\mathrm{CD} 44^{+/+}$mice. Mice were immunized and subsequently challenged in one footpad with PPD, after which the swelling of footpads was measured. Both $C D 44^{+/+}$ and $C D 44^{-/-}$mice showed significant footpad thickening after the challenge. Surprisingly, swelling responses in $\mathrm{CD} 44^{-/-}$mice were twice as high as in $\mathrm{CD} 44^{+/+}$mice (Figure $8 \mathrm{a}$ ). Histological analysis revealed a pronounced edema in the footpads of $C D 44^{-/-}$mice accompanied by a dense and diffuse inflammatory infiltrate (Figure 8c) predominantly composed of PMNs (Figure 8e). The footpads of $\mathrm{CD}_{4} 4^{+/+}$mice, however, showed the classical histological picture of a DTH reaction with a quite welldefined inflammatory infiltrate limited to the subcutis, with slight edema (Figure $8 \mathrm{~b}$ ) that was primarily composed of mononuclear cells (Figure 8f).

\section{Discussion}

Cell migration and phagocytosis are both critically dependent on cytoskeletal rearrangements and are important for resistance against tuberculosis. Since CD44 is an adhesion molecule involved in inflammatory processes and is linked to the actin cytoskeleton, we investigated the role of CD44 in both these processes during pulmonary tuberculosis. The deficiency of CD44 led to a profound defect in the early recruitment of $\mathrm{M} \phi \mathrm{s}$, and to a more modest reduction in the influx of lymphocytes to the pulmonary compartment. In addition, CD44 was identified as a site on M $\phi$ s that is important for binding and subsequent uptake of $M$. tuberculosis. We further demonstrated that CD44 plays a role in the protective immune response to pulmonary tuberculosis in vivo, as indicated by a reduced survival and an enhanced mycobacterial outgrowth in lungs and livers of $\mathrm{CD} 44^{-/-}$mice.

The present study demonstrates a strong reduction of $\mathrm{M} \phi$ numbers in lungs of $C D 44^{-/-}$mice early in the infection, indicating that CD44 promotes M $\phi$ recruitment
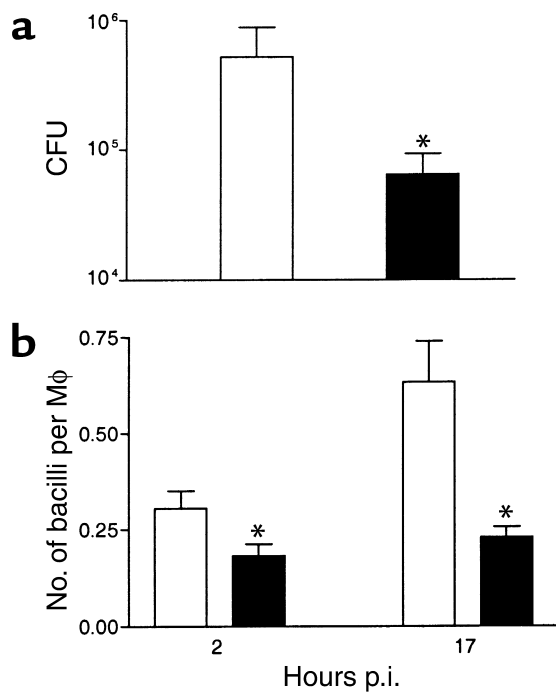

\section{Figure 4}

CD44 is involved in binding and phagocytosis of $M$. tuberculosis by

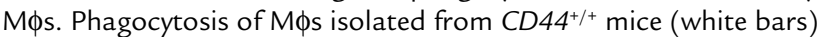
and $\mathrm{CD} 44^{-/-}$mice (black bars) examined by counting CFUs ( $\mathrm{MOI}$ of 10 , a) or intracellular acid-fast bacilli (MOI of $2, \mathbf{b})$. Data are shown as mean \pm SEM of five mice per group. ${ }^{*} P<0.05$ vs. control. 


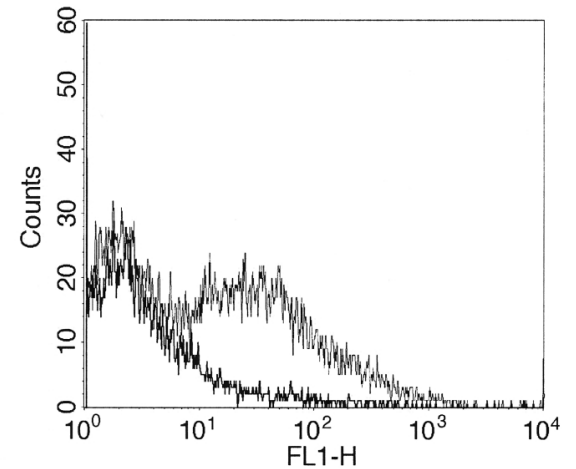

\section{Figure 5}

Binding of CD44 to M. tuberculosis bacilli. Mycobacteria were incubated with (thin line) or without (thick line) recombinant human CD44std for 30 minutes at $37^{\circ} \mathrm{C}$, after which binding of CD44 was detected with FITC-labeled anti-human CD44std Ab and quantitated by flow cytometry. Fluorescence intensity shift was seen for the binding of human CD44std to M. tuberculosis (about three times higher than the control).

to the site of mycobacterial infection. In accordance with this finding, an earlier study showed that shedding of $\mathrm{CD} 44 \mathrm{by} \mathrm{Ab}$ treatment led to a reduction of mononuclear cell influx into the CNS during experimental allergic encephalomyelitis (16). In keeping with this migration of $C D 44^{-/-} \mathrm{M} \phi$ s into atherosclerotic lesions was reduced (29). In contrast, inhibition of binding of CD44 to its main ligand, hyaluronate, did not influence influx of monocytes and $M \phi s 16$ hours after intraperitoneal administration of SEB (6). This suggests that migration of M $\phi$ s is mediated by CD44 but can be independent of hyaluronate. Presumably, other CD44 ligands, like fibronectin (30), osteopontin (31), or collagen types I and $\operatorname{IV}(30,32)$, are more important for $\mathrm{M} \phi$ migration via $\mathrm{CD} 44$. The observation that $\mathrm{M} \phi$ numbers were similar in $\mathrm{CD} 44^{-/-}$mice compared with $\mathrm{CD} 44^{+/+}$mice later in the infection may reflect a relative deficiency in $\mathrm{M} \phi$ influx, since the bacterial load was higher in $C D 44^{-/-}$ mice 5 weeks p.i. CD44 might also be important only in the early phase of migration and/or be compensated for by other adhesion receptors. Apparently, this early phase is important for the outcome of the disease.

$\mathrm{CD} 44^{-/-} \mathrm{M} \phi s$ not only demonstrated a reduced migration to the site of infection but also were found to be less capable of binding and phagocytosing $M$. tuberculosis. Indeed, we provide, for the first time to our knowledge evidence that CD44 is a receptor on $M \phi s$ for binding of $M$. tuberculosis. We demonstrated that soluble CD44 directly binds to M. tuberculosis and that CD44 expressed on M $\phi$ s supports binding and subsequent phagocytosis of mycobacteria. CD44 has already been shown to be involved in phagocytosis of heat-killed Staphylococcus aureus by human PMNs (9), and of apoptotic PMNs by human monocyte-derived M $\phi$ s (10). Furthermore, group A Streptococcus has been demonstrated to bind keratinocyte CD44 to induce cytoskeleton changes that promote tissue invasion of these bacteria (33). Our finding that CD44 mediates $M \phi$ binding of $M$. tuberculosis defines a novel and immunologically important function for CD44. Additional studies of the function of CD44 may be needed to determine how binding by CD 44 modulates $M \phi$ bactericidal functions.

The impaired mycobacterial clearance in $\mathrm{CD} 44^{-/-}$mice was also associated with a reduced lymphocyte percentage in lungs late in the infection. The importance of CD44 on lymphocytes during mycobacterial infections is suggested by observations of increased numbers of pulmonary $\mathrm{CD} 44^{+} \mathrm{T}$ lymphocytes during lung tuberculosis $(18-20,34)$ that adoptively transferred protection against $M$. tuberculosis when obtained from mice vaccinated with mycobacterial heat-shock protein-65 (35-37). In line with the present findings, CD44 was also involved in the extravasation of activated antigenspecific $T$ cells to the SEB-inflamed peritoneal cavity (6). A possible explanation for the fact that $\mathrm{CD}_{4} 4^{-/}$mice displayed only modestly reduced lymphocyte numbers may be found in the higher mycobacterial load in the $\mathrm{CD} 44^{-/-}$animals than in $\mathrm{CD} 44^{+/+}$mice. Furthermore, adoptive transfer experiments of Silva and Lowrie suggest that protection against $M$. tuberculosis is IFN- $\gamma$ dependent (37). Consistently, we found lower IFN- $\gamma$ levels in lungs of infected $\mathrm{CD} 44^{-/}$animals.

Granulomas are well-organized structures composed of aggregated $M \phi s$, lymphocytes, and epithelioid cells; they are known to wall off the infectious site and to prevent further spreading (38). We found that mice deficient in CD44 form less well-shaped granulomas than do $C D 44^{+/+}$mice. Accordingly, $C D 44^{-/-}$mice had more mycobacteria disseminated to their livers than $C D 44^{+/+}$ mice. CD44 has already been shown to mediate cell aggregation via inter-CD44 binding or multivalent hyaluronan binding by $\mathrm{CD} 44$ on neighboring cells (39). Additionally, hyaluronan-dependent binding has been demonstrated to cause aggregation of M $\phi$ s and lymphocytes $(40,41)$. Differentiated M $\phi$-epithelioid cells in granulomas even produce ECM proteins like osteopontin and fibronectin (42), which are natural ligands for CD44. Apparently, cell aggregation in the development of granulomas is partly regulated by $\mathrm{CD} 44$.
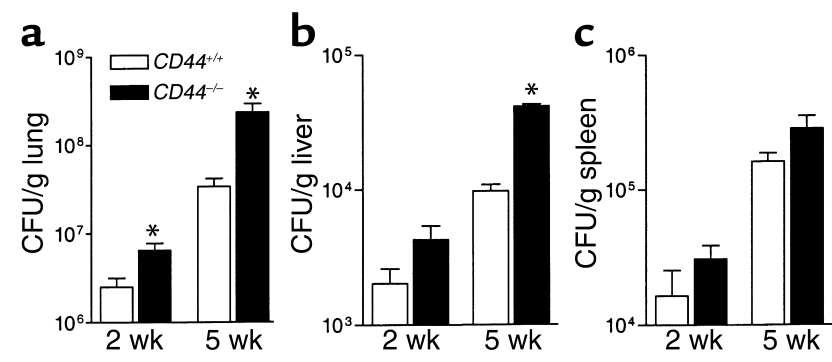

\section{Figure 6}

Effect of CD44 deficiency on the mycobacterial outgrowth in lungs, liver, and spleen of mice infected with $M$. tuberculosis. Mice were intranasally administered with $1 \times 10^{5} \mathrm{M}$. tuberculosis H37Rv. Data are shown as mean \pm SEM of eight mice. ${ }^{*} P<0.05$ vs. control. 


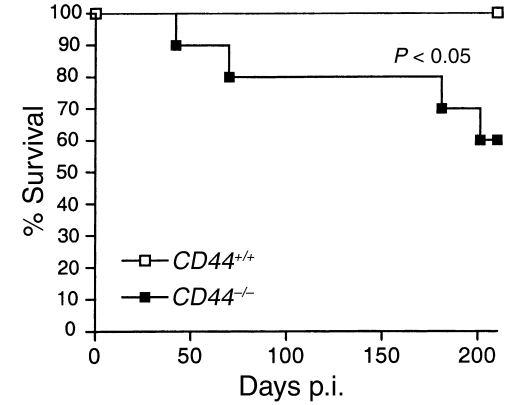

Figure 7

Effect of CD44 deficiency on survival. CD44 ${ }^{+/+}$and CD44-/- mice ( $n=10$ per group) were intranasally infected with $1 \times 10^{5} \mathrm{M}$. tuberculosis H37Rv and followed for 7 months.

The inability of $\mathrm{CD} 44^{-/-}$mononuclear cells to efficiently migrate to inflammatory sites was more extensively studied in footpad DTH responses to PPD. This demonstrated that infiltration of mononuclear cells at the site of antigen challenge was reduced in immunized $C D 44^{-/-}$mice compared with $C D 44^{+/+}$mice, whereas the influx of PMNs and swelling were increased. This further supports the concept that CD44 participates in the recruitment of mononuclear cells to sites of inflammation. Strikingly, in both the M. tuberculosis infection experiment and the DTH experiment, the number of PMNs in $\mathrm{CD} 44^{-/-}$mice was greatly enhanced compared with that in $\mathrm{CD} 44^{+/+}$mice, suggesting that the lack of $M \phi$ and lymphocyte influx at the site of inflammation in $\mathrm{CD} 44^{-/-}$mice may lead to enhanced PMN migration in a CD44-independent compensatory response. Other possible explanations for the PMN influx may be enhanced survival of these cells as a consequence of diminished CD44-mediated apoptosis of neutrophils (43), impaired ability of CD44-deficient M $\phi$ s to ingest apoptotic PMNs (44), and reduced CD44-mediated removal of pulmonary hyaluronan fragments (44) which have proinflammatory functions (45). Further experimental work is necessary to distinguish between these possibilities.

\footnotetext{
Figure 8

(a) DTH response in footpads of mice. CD44 $4^{+/}$(white bar) and CD44-/- (black bar) mice were immunized with heat-killed M. tuberculosis and challenged in one hind footpad with PPD and in the other with saline. Footpad swelling was measured 0 and 24 hours after the antigen challenge and calculated as described in Methods. Data are shown as mean \pm SEM of five mice. ${ }^{*} P<0.05$ vs. control. (b) Representative view of the footpad of a $C D 44^{+/+}$mouse 48 hours after a DTH reaction, showing a classical picture of a DTH reaction: a demarcated inflammatory infiltrate with slight edema (original magnification, $\times 50$; H\&E staining). (c) Histological analysis of the footpad of a $C D 44^{-/-}$mouse demonstrated a dense and diffuse inflammatory infiltrate together with a pronounced edema. (d-g) Immunohistochemical detection of PMNs ( $\mathbf{d}$ and $\mathbf{e})$ and mononuclear cells ( $\mathbf{f}$ and $\mathbf{g}$ ) in DTH footpads showed that the inflammatory infiltrate of $C D 44^{-/-}$ mice was mostly composed of PMNs (e; original magnification, $\times 100$ ), whereas mononuclear cells were the predominant cell type found in $C D 44^{+/+}$mice (f; original magnification, $\left.\times 100\right)$.
}

We found enhanced IFN- $\gamma$ release by PPD-stimulated splenocytes from infected $\mathrm{CD} 44^{-/-}$mice. Generally, a type 1 cytokine response predominates early in the infection in spleens of mice infected with M. tuberculosis. Later during infection, this type 1 response declines, and by the time a latent infection is established, a type 2 response prevails (46), giving rise to speculation that protective type 1 cells migrate from the spleen to the infected lungs (47). We found an increase in type 1 splenocytes of CD44-/- mice both early and late in the infection. This suggests that migration and/or adhesion of splenocytes to the lungs of $\mathrm{CD} 44^{-/}$mice is impaired, which is in line with the lower number of lung lymphocytes and the reduced IFN- $\gamma$ levels in the lungs of these animals. The similar mycobacterial loads in the spleens of $\mathrm{CD}_{44^{-/} \text {and }}$ $\mathrm{CD} 44^{+/+}$mice (the anticipated higher mycobacterial numbers were not found) may reflect a protective function of IFN- $\gamma$-producing splenocytes against $M$. tuberculosis.

The present report provides strong evidence that CD44 exerts protective effects against $M$. tuberculosis. Interestingly, in other studies, blocking of adhesion molecules other than CD44 did not influence the clearance of mycobacteria. When ICAM-1-/- mice and mice treated with $\mathrm{mAb}$ to $\alpha_{4}$ or $\alpha_{4} \beta_{7}$ integrin were infected aerogenically with $M$. tuberculosis, they displayed mycobacterial growth in lungs that was similar to the growth in their respective control mice $(19,21)$. $P$-selectin ${ }^{-/}$and/or ICAM-1-/- mice systemically infected with $M$. bovis also showed an unaltered clearance of mycobacteria (22), and mice deficient in complement receptor 3 , a $\beta_{2}$ integrin, did not differ from wild-type

\section{a}
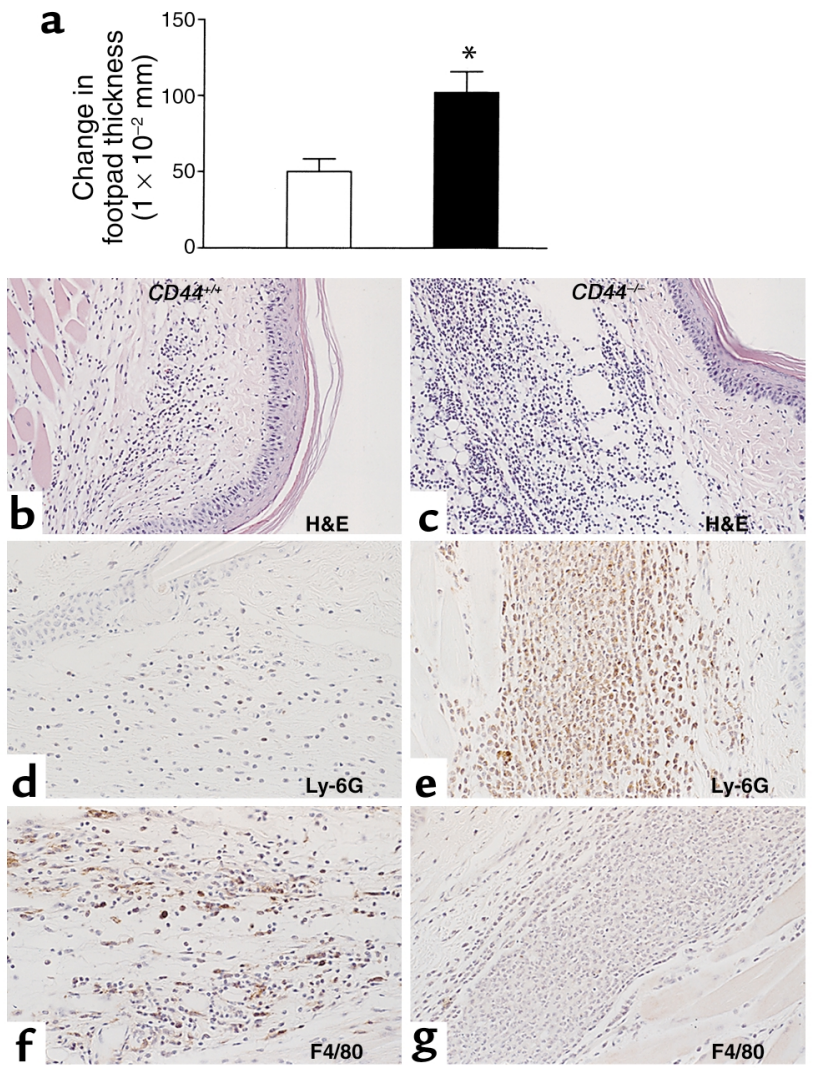
mice with respect to survival and bacterial burden during $M$. tuberculosis infection (23). Thus the present study identifies a unique function for CD44 as an adhesion molecule in mediating resistance against mycobacterial infection, presumably by promoting binding and phagocytosis of $M$. tuberculosis by $M \phi s$ and migration of Mps to the site of infection.

\section{Acknowledgments}

The authors wish to thank Joost Daalhuisen, Nike Claessen, and Tessa ten Hove for expert technical assistance and advice. This work was supported by a grant from The Netherlands Organization for Scientific Research (to J.C. Leemans).

1. World Health Organization. 1994. Global comparative assessments in the health sector: disease burden, expenditures and intervention packages. Murray, C.J.L., and Lopez, A.D., editors. World Health Organization. Geneva, Switzerland. $196 \mathrm{pp}$.

2. Dye, C., Scheele, S., Dolin, P., Pathania, V., and Raviglione, M.C. 1999. Consensus statement. Global burden of tuberculosis: estimated incidence, prevalence, and mortality by country. WHO Global Surveillance and Monitoring Project. JAMA. 282:677-686.

3. World Health Organization. 2001. Global tuberculosis control. WHO Report 2001. Geneva, Switzerland. WHO/CDS/TB/2001.287. 173 pp.

4. Flynn, J.L., and Chan, J. 2001. Immunology of tuberculosis. Annu. Rev. Immunol. 19:93-129.

5. Kaufmann, S.H., and Hess, J. 2000. Immune response against mycobacterium tuberculosis: implications for vaccine development. J. Biotechnol. 83:13-17.

6. DeGrendele, H.C., Estess, P., and Siegelman, M.H. 1997. Requirement for CD44 in activated $\mathrm{T}$ cell extravasation into an inflammatory site. Science. 278:672-675.

7. Camp, R.L., Scheynius, A., Johansson, C., and Pure, E. 1993. CD44 is necessary for optimal contact allergic responses but is not required for normal leukocyte extravasation. J. Exp. Med. 178:497-507.

8. Goodison, S., Urquidi, V., and Tarin, D. 1999. CD44 cell adhesion molecules. Mol. Pathol. 52:189-196.

9. Moffat, F.L., et al. 1996. Involvement of CD44 and the cytoskeletal linker protein ankyrin in human neutrophil bacterial phagocytosis. J. Cell. Physiol. 168:638-647.

10. Hart, S.P., Dougherty, G.J., Haslett, C., and Dransfield, I. 1997. CD44 regulates phagocytosis of apoptotic neutrophil granulocytes, but not apoptotic lymphocytes, by human macrophages. J. Immunol. 159:919-925.

11. Lesley, J., and Hyman, R. 1998. CD44 structure and function. Front. Biosci. 3:D616-D630.

12. Haynes, B.F., Hale, L.P., Patton, K.L., Martin, M.E., and McCallum, R.M 1991. Measurement of an adhesion molecule as an indicator of inflammatory disease activity. Up-regulation of the receptor for hyaluronate (CD44) in rheumatoid arthritis. Arthritis Rheum. 34:1434-1443.

13. Zeidler, A., et al. 1995. Therapeutic effects of antibodies against adhesion molecules in murine collagen type II-induced arthritis. Autoimmunity. 21:245-252.

14. Mikecz, K., Brennan, F.R., Kim, J.H., and Glant, T.T. 1995. Anti-CD44 treatment abrogates tissue oedema and leukocyte infiltration in murine arthritis. Nat. Med. 1:558-563.

15. Stoop, R., Kotani, H., McNeish, J.D., Otterness, I.G., and Mikecz, K. 2001. Increased resistance to collagen-induced arthritis in CD44-deficient DBA/1 mice. Arthritis Rheum. 44:2922-2931.

16. Brennan, F.R., et al. 1999. CD44 is involved in selective leucocyte extravasation during inflammatory central nervous system disease. Immunolo gy. 98:427-435.

17. Blass, S.L., Pure, E., and Hunter, C.A. 2001. A role for CD44 in the production of IFN-gamma and immunopathology during infection with Toxoplasma gondii. J. Immunol. 166:5726-5732.

18. Lyadova, I., et al. 1998. An ex vivo study of T lymphocytes recovered from the lungs of I/St mice infected with and susceptible to Mycobacterium tuberculosis. Infect. Immun. 66:4981-4988.

19. Feng, C.G., et al. 2000. Up-regulation of VCAM-1 and differential expansion of beta integrin-expressing $\mathrm{T}$ lymphocytes are associated with immunity to pulmonary Mycobacterium tuberculosis infection. J. Immunol. 164:4853-4860.

20. Feng, C.G., Bean, A.G., Hooi, H., Briscoe, H., and Britton, W.J. 1999.
Increase in gamma interferon-secreting CD8(+), as well as CD4(+), T cells in lungs following aerosol infection with Mycobacterium tuberculosis. Infect. Immun. 67:3242-3247.

21. Johnson, C.M., Cooper, A.M., Frank, A.A., and Orme, I.M. 1998. Adequate expression of protective immunity in the absence of granuloma formation in Mycobacterium tuberculosis-infected mice with a disruption in the intracellular adhesion molecule 1 gene. Infect. Immun. 66:1666-1670.

22. Steinhoff, U., Klemm, U., Greiner, M., Bordasch, K., and Kaufmann, S.H. 1998. Altered intestinal immune system but normal antibacterial resistance in the absence of P-selectin and ICAM-1. J. Immunol. 160:6112-6120.

23. Hu, C., Mayadas-Norton, T., Tanaka, K., Chan, J., and Salgame, P. 2000. Mycobacterium tuberculosis infection in complement receptor 3-deficient mice. J. Immunol. 165:2596-2602.

24. Schmits, R., et al. 1997. CD44 regulates hematopoietic progenitor distribution, granuloma formation, and tumorigenicity. Blood. 90:2217-2233.

25. Juffermans, N.P., et al. 2000. Interleukin-1 signaling is essential for host defense during murine pulmonary tuberculosis. J. Infect. Dis. 182:902-908

26. Leemans, J.C., et al. 2001. Depletion of alveolar macrophages exerts protective effects in pulmonary tuberculosis in mice. J. Immunol. 166:4604-4611.

27. Clemens, D.L., Lee, B.Y., and Horwitz, M.A. 2000. Mycobacterium tuberculosis and Legionella pneumophila phagosomes exhibit arrested maturation despite acquisition of Rab7. Infect. Immun. 68:5154-5166.

28. Kerr, J.R. 1999. Cell adhesion molecules in the pathogenesis of and host defence against microbial infection. Mol. Pathol. 52:220-230.

29. Cuff, C.A., et al. 2001. The adhesion receptor CD44 promotes atherosclerosis by mediating inflammatory cell recruitment and vascular cell activation. J. Clin. Invest. 108:1031-1040. doi:10.1172/JCI200112455.

30. Jalkanen, S., and Jalkanen, M. 1992. Lymphocyte CD44 binds the COOH-terminal heparin-binding domain of fibronectin. J. Cell Biol. 116:817-825.

31. Weber, G.F., Ashkar, S., Glimcher, M.J., and Cantor, H. 1996. Receptorligand interaction between CD44 and osteopontin (Eta-1). Science. 271:509-512.

32. Carter, W.G., and Wayner, E.A. 1988. Characterization of the class III collagen receptor, a phosphorylated, transmembrane glycoprotein expressed in nucleated human cells. J. Biol. Chem. 263:4193-4201.

33. Cywes, C., and Wessels, M.R. 2001. Group A Streptococcus tissue invasion by CD44-mediated cell signaling. Nature. 414:648-652.

34. Lesley, J., Hyman, R., and Kincade, P.W. 1993. CD44 and its interaction with extracellular matrix. Adv. Immunol. 54:271-335.

35. Bonato, V.L., Lima, V.M., Tascon, R.E., Lowrie, D.B., and Silva, C.L. 1998. Identification and characterization of protective T cells in hsp65 DNAvaccinated and Mycobacterium tuberculosis-infected mice. Infect. Immun. 66:169-175.

36. Silva, C.L., Bonato, V.L., Lima, V.M., Faccioli, L.H., and Leao, S.C. 1999. Characterization of the memory/activated T cells that mediate the longlived host response against tuberculosis after bacillus Calmette-Guerin or DNA vaccination. Immunology. 97:573-581.

37. Silva, C.L., and Lowrie, D.B. 2000. Identification and characterization of murine cytotoxic T cells that kill Mycobacterium tuberculosis. Infect. Immun. 68:3269-3274.

38. Orme, I.M., and Cooper, A.M. 1999. Cytokine/chemokine cascades in immunity to tuberculosis. Immunol. Today. 20:307-312.

39. Cooper, D.L., and Dougherty, G.J. 1995. To metastasize or not? Selection of CD44 splice sites. Nat. Med. 1:635-637.

40. Green, S.J., Tarone, G., and Underhill, C.B. 1988. Aggregation of macrophages and fibroblasts is inhibited by a monoclonal antibody to the hyaluronate receptor. Exp. Cell Res. 178:224-232.

41. Underhill, C., and Dorfman, A. 1978. The role of hyaluronic acid in intercellular adhesion of cultured mouse cells. Exp. Cell Res. 117:155-164.

42. Nau, G.J., et al. 1997. A chemoattractant cytokine associated with granulomas in tuberculosis and silicosis. Proc. Natl. Acad. Sci. U. S. A. 94:6414-6419.

43. Takazoe, K., et al. 2000. CD44-mediated neutrophil apoptosis in the rat. Kidney Int. 58:1920-1930.

44. Teder, P., et al. 2002. Resolution of lung inflammation by CD44. Science. 296:155-158.

45. McKee, C.M., et al. 1996. Hyaluronan (HA) fragments induce chemokine gene expression in alveolar macrophages. The role of HA size and CD44. J. Clin. Invest. 98:2403-2413.

46. Howard, A.D., and Zwilling, B.S. 1998. Cytokine production by CD4 and CD8 T cells during the growth of Mycobacterium tuberculosis in mice. Clin. Exp. Immunol. 113:443-449.

47. Morikawa, Y., Tohya, K., Ishida, H., Matsuura, N., and Kakudo, K. 1995. Different migration patterns of antigen-presenting cells correlate with Th1/Th2-type responses in mice. Immunology. 85:575-581. 